\title{
Research on Renewable Energy in Shandong Province
}

\author{
Hongtao Liu ${ }^{1, a}$,Yingwei Chi ${ }^{1, b}$, Li Xue ${ }^{1, ~ c}$,Dengfeng $\mathrm{Xu}^{1,}$, ,Jinxiao $\mathrm{Li}^{2, \mathrm{e}}$ \\ ${ }^{1}$ SEPCO Electric Power Construction Corporation,250014 Jinan, China \\ ${ }^{2}$ School of Energy and Power Engineering,Shandong University, 250061 Jinan, China

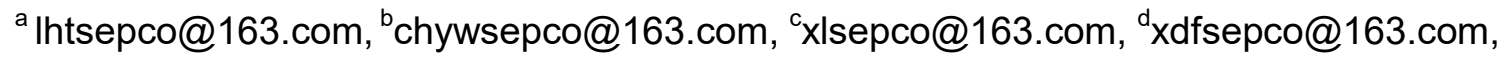 \\ elijinxiao.fc@163.com
}

\begin{abstract}
Keywords: renewable energy, energy policy, energy resources, energy consumption, energy exploit and utilization

Abstract. Shandong is a major province located in eastern China, which has large population, prosperous economy and great energy consumption. For better development, more information should be gathered for politic making or energy planning. In this paper, a large amount of information was searched on bibliographic data base. In the meantime, field researches were carried out in large power enterprise, electric power design institute, research institute and relative administrative departments. Some renewable energy status in Shandong was introduced, such as solar energy, biomass energy, wind energy, geothermal energy, hydropower and marine energy. Problems and shortages were also put forward and some solutions were given at the same time.
\end{abstract}

\section{Introduction}

According to World Energy Look 2016 made by International Energy Agency, global energy consumption will increase by $30 \%$ till 2040. However, Paris Agreement calls for reductionof carbon emission inthe coming decades. So the world energy structure is facing a transition to fulfill both the increase of energy demand and the decrese of the carbon emission, and renewable energy will become more and more important in future energy structrue.

Under such circumstances, renewable energy will take the place of fossil fuels and turn into main energy in the future. What's more, the development of renewable energy will form new industral chain, provide more jobs and provide new economic development point. On the basis of some calculation, renewable energy equipment manufacturing industry will provide more than 300 thounsand job and annual value of production will come to more than $1.45 \times 10^{8}$ Sin Shandong Provice[1]. As we can see from Table 1, the proportion of renewable energy will be much more in the near future in Shandong. Accroding to Shandong Medium and Long Term Energy Plansmadein 2016, till 2020, the consumption porperty of new energy and renewable energy will be raised from $3 \%$ to $7 \%$, and the number is surely going up to $18 \%$ until 2030 . Therefore, the effective utiliazation of renewable energy becomes a new hot spot.

Table1 Plans for installed electricity capacity in Shandong Province $\left[1 \times 10^{4} \mathrm{~kW}\right]$

\begin{tabular}{|c|c|c|c|}
\hline Category & Target & 2020 & 2030 \\
\hline \multirow{2}{*}{ Fossil energy } & Coal Power & 10000 & 10000 \\
\cline { 2 - 4 } & Gas Power & 400 & 10000 \\
\hline \multirow{3}{*}{$\begin{array}{c}\text { Renewable } \\
\text { energy }\end{array}$} & Wind Power & 1400 & 2300 \\
\cline { 2 - 4 } & Solar PV Power & 1000 & 2500 \\
\cline { 2 - 4 } & Nuclear Power & 270 & 2065 \\
\cline { 2 - 4 } & Biomass Power & 230 & 500 \\
\cline { 2 - 4 } & Hydropower & 110 & 790 \\
\hline Surplus energy & Installed capacity & 350 & 400 \\
\hline
\end{tabular}




\section{Energy Resources and Consumption Status}

Located in eastern coast of China, Shandong is an economy-prosperous province. In order to fit the rapid growth of economy, energy consumption in Shandon is also going up. The total energy consumption amount in 2014 is equate to standard coal for $3.65 \times 10^{6}$ tons, which is $20.9 \%$ more than 2010. Setting 2005 as a base period, the amount of energy consumption increases by $1.4 \times 10^{5}$ tons' standard coal every year, and the annual growth rate is $4.7 \%$. Coal is in the absolute predominance in energy consumption, and secondary industry consumes more energy. In 2014, the energy consumption of secondary industry is $2.81 \times 10^{8}$ tons' standard coal, which makes up $77 \%$ of all the energy consumption [2].

Table 2 Primary Energy Output in Major Years

\begin{tabular}{cccccc}
\hline Year & $\begin{array}{c}\text { Total energy } \\
\text { production }\end{array}$ & Coal & Crude Oil & Natural Gas & $\begin{array}{c}\text { Renewable } \\
\text { Energy }^{[1]}\end{array}$ \\
\hline 1999 & 10322.39 & 6425.10 & 3807.55 & 89.01 & 0.73 \\
2004 & 14394.61 & 10461.78 & 3820.50 & 111.84 & 0.49 \\
2009 & 14600.08 & 10424.07 & 4040.38 & 119.97 & 15.66 \\
2014 & 15220.40 & 10699.80 & 3876.09 & 62.89 & 133.13 \\
\hline
\end{tabular}

[1] Renewable energy: Hydro, Wind and Solar PV(PV) Power

The amount of coal consumption is always beyond $70 \%$ in Shandong Province, while the consumption of natural gas and petroleum are below the national average. According to Table 2, renewable energy such as hydropower, wind energy and solar energy are just used as auxiliary energy source at least for a short term, and nuclear power construction is also hard to make big break through during a short period.

\section{The Development of Renewable Energy}

Solar energy

The utilization of solar energy in Shandong Province is mainly focused on PV power generation and heat utilization. At present, the production of solar water heater has already formed a thorough industrial system which include raw material processing, technological development, production and marketing service. In the meantime, relevant industry such as glassmaking, metal manufacturing, insulation material, vacuum equipment were promoted as well. Solar equipment firms reached a certain scale in Shandong are more than 110. What's more, the sales of Himin Solar Energy, Ritter Solar, Sangle solar energy, Ecoo Solar are in the top ten all over the country.

By June, 2016, the PV generating capacity of Shandong power grid reached $2.82 \times 10^{5} \mathrm{~kW}$. The number of centralized PV power station is 87 , and their capacity are $2.1 \times 10^{5} \mathrm{~kW}$, the year-on-year growth is $402 \%$. The number of distributed PV power station is 3895 , and their capacity are up to $7.25 \times 10^{5} \mathrm{~kW}$, the year-on-year growth is $161 \%$ [3]. Till 2020, the total PV power installed capacity in Shandong Province will be $1 \times 10^{7} \mathrm{~kW}$, of which PV power station will be $8 \times 10^{6} \mathrm{~kW}$, and distributed PV power generation will be $2 \times 10^{6} \mathrm{~kW}$. Till 2030 , the total capacity will be $2.5 \times 10^{7} \mathrm{~kW}$, of which PV station will increase to $1 \times 10^{7} \mathrm{~kW}$.

Biomass energy

In 2006, the biomass power generation project was put into operation in Shanxian, Shandong Province. It was the first time to construct a biomass power plant by adopting advanced technology from other countries and using crop stalks and wood wastes as raw materials in China. Its installed capacity is $2.5 \times 10^{4} \mathrm{~kW}$, annual power generation is $1.4 \times 10^{8} \mathrm{kWh}$, which cost crop stalks for $1.6 \times 10^{5}$ tons and reduce $\mathrm{CO}_{2}$ emissionfor $1 \times 10^{5}$ tons per year. The annual benefit of the project is more than $4.35 \times 10^{6} \$[4]$. 
By the end of 2015, the number of biomass power plant (garbage power plant included) is 87 , whose generating capacity are up to $1.16 \times 10^{6} \mathrm{~kW}$, and the year-on-year growth is $18.57 \%$. Their annual energy production is $6.24 \times 10^{8} \mathrm{kWh}$, and the year-on-year growth is $25.02 \%$ [5].

For further development, measures should suit to local conditions. All of the crop straw, municipal waste, forest, and livestock manure can be gathered for power generation. Till 2020, the total biomass installed capacity will be $2.3 \times 10^{6} \mathrm{~kW}$. For 2030 , the number will be $5 \times 10^{6} \mathrm{~kW}$.

Wind energy

Shandong is one of the most areas abundant in wind energy. The total amount of wind energy in Shandong is about $6.7 \times 10^{7} \mathrm{~kW}$, and mainly concentrated on the coast, island and plain areas in the mountains. Offshore wind energy in Shandong is more abundant than land, and it has high speed, long period and high efficiency, which makes great potential.

With governments at all levels paying their attention to wind energy, the wind power industry in Shandong Province is developing rapidly. By 2015 , the grid-tied totally installed capacity added up to $7.21 \times 10^{6} \mathrm{~kW}$, generating capacity come to $1.21 \times 10^{9} \mathrm{kWh}$, approved cumulative capacity is $1.31 \times 10^{7}$ $\mathrm{kW}$, and the year-on-year growth is $2.486 \times 10^{6} \mathrm{~kW}$. The cumulative capacity under construction is $5.9 \times 10^{6} \mathrm{~kW}$, and the year-on-year growth is $1.42 \times 10^{6} \mathrm{~kW}$. What's more, 5 offshore megawatts wind power bases will be managed to build as demonstration projects to encourage the construction of wind power. Shandong government also plans to realize the goal that the installed capacity of wind-driven power should reach $1.4 \times 10^{7} \mathrm{~kW}$ by 2020 , and $2.9 \times 10^{7} \mathrm{~kW}$ by $2030[6]$.

Geothermal energy

There is abundant geothermal energy in Shandong Province. According to research, the quantity of geothermal energy in Shandong equates to standard coal for $1.24 \times 10^{10}$ tons, of which the available quantity equates to standard coal for $1.34 \times 10^{9}$ tons. The reserves of geothermal energy are far more than petroleum and coal, which ranks only second to natural gas. So far the utilization amount is $8.12 \times 10^{5}$ tons, which is less than ten thousandth of the available quantity, and the main usage are heating, bathing, swimming and aquiculture. If exploit all the geothermal water in 100 years, $1.005 \times 10^{10} \mathrm{~m}^{3}$ will be recovered per day.

Shandong is abundant in low-medium temperature geothermal energy. According to research, 17 cities in Shandong have geothermal energy, which is concentrated on plains in western and northwestern Shandong. Dezhou, DongYing, Binzhou, Liaocheng and Heze have the most abundant geothermal energy, next are Jinan, Zibo, Jining and Weifang. The use ratio of geothermal energy in these cities are badly uneven [7].

The usage of geothermal energy can be more diverse. For example, geothermal energy can be taken as heat source for heat supply, greenhouse cultivation and leisure resort. Measures such as combined utilization and energy-step-utilization could be adopt for further development. The heating(cooling) area based on geothermal will be $1.5 \times 10^{8} \mathrm{~m}^{3}$ in 2020 , and it will be $3 \times 10^{8} \mathrm{~m}^{3}$ in 2030 .

Hydropower

The theoretical content of inland hydropower resources in Shandong Province is $4.4 \times 10^{5} \mathrm{kWh}$, of which the exploitable amount is $2.14 \times 10^{5} \mathrm{kWh}$. Till 2010 , there were 218 hydropower stations, 345 generator units, and totally installed capacity for $77449 \mathrm{~kW}$. Small hydropower stations whose $\mathrm{N} \geq 500 \mathrm{~kW}$ ( $\mathrm{N}$ means installed capacity) were 85 , generator units were 177, and installed capacity are up to $59109 \mathrm{~kW}$. Small hydropower stations whose $\mathrm{N}<500 \mathrm{~kW}$ were 133, generator units were 168 . Until now, the number of small hydropower stations merged into power grid is 148 , and installed capacity is $70806 \mathrm{~kW}$ [8].

Marine energy

Shandong Peninsula has a very twisting coastline, which is $3000 \mathrm{~km}$ and account for one-six of the coastline in China. For this reason, Shandong has been built up the Blue Economic Zone to take full advantage of marine resources. Since 1950s, Shandong has conducted a series of preliminarily exploration on marine energy, such as Baishakou tidal power station in Rushan, whose annual power generation reached $2.3 \times 10^{6} \mathrm{kWh}$. 
At present, the development and utilization of ocean wave power in Shandong Province is at forefront of the country. The $100 \mathrm{~kW}$ pendulum wave power station in Daguan Island, Jimo City had been put in to operation in September, 1999, whose annual power generation was $8 \times 10^{5} \mathrm{kWh}$. Compared to equivalent coal-fired power plants, it can save coal resources for more than $3.5 \times 10^{6}$ tons per year. And so far it can provide power for more than 30 families, 120 people or so for daily life. For the exploit of ocean thermal energy, the first seawater source heat pump system in China was built in Qingdao. The price for heating of this system is cheaper than coal heating for $1.45 \$ / \mathrm{m}^{2}$. Qingdao Olympic sailing competition base had adopted this system for power during 2008 Beijing Olympic Games [9].

\section{Problems and Shortage}

Policy

Renewable energy policies in Shandong Province are relatively single, more measures should be put forward to encourage the development of renewable energy. Most policies are simply imitations, which have less definite goal and practicable measures. Innovation mechanism and high-end platform should be built up immediately, and the energy structure should be accelerated. Not only the energy saving products should be popularize, but also the energy saving ideas should be instilled in people.

Theory

The policymaking study are mostly based on theoretical researches, empirical experiments are badly insufficient, which leave a lot to be desired. If there are enough data and cases, more valuable conclusions will derive persuasive theoretical research and operability policy.

At present, peak regulation ability of power grid is still weak for our country, and the utilization ratio of renewable energy is pretty low. Take wind energy as an example, although the installed capacity is at advanced level, the wind abandoning rate is also high. Backward technique is the main reason to restrict the development of renewable energy, which makes it the core competitiveness. Therefore, related service and technology should be developed and investment should be strengthened to solve the cost and stability problems.

\section{Conclusions}

Shandong has abundant renewable energy resources and extensive market, which makes it a huge potential to develop renewable energy industry. But there are still so many problems in policy, theory and technology. More measures should be taken in the flowing stage of development.

\section{References}

[1]Xiaomei Yang, Mingxian Xu, Changgao Sun, Bing Wei, Yijun Ma, Jizhe Zheng: Shandong Industrial Technology, Vol.01(2014), p.72. (In Chinese)

[2] An Wang, Fuyi Gao and Jihai Yu: Financial Development Research, Vol.8(2016), p.83-85. (In Chinese)

[3]Information on http://guangfu.bjx.com.cn/news/20160816/762796.shtml(In Chinese)

[4]Yinghao Zhao: Study on Resource Evaluation and Industry Development of Biomass in Shandong.[D] Shandong University,2015. (In Chinese)

[5]Information on http://guangfu.bjx.com.cn/news/20160121/703562.shtml. (In Chinese)

[6]Information on http://www.ocn.com.cn. (In Chinese)

[7]Information onhttp://www.sd.xinhuanet.com/news/2009-06/30/content_16952513.htm. 
[8]Mengjun Li: Renovation Decision Research on Small Hydropower Station in Shandong Province[D]. ShandongAgriculturalUniversity, 2015. (In Chinese)

[9] Information on:http://news.sdchina.com/show/227555.html. (In Chinese) 